\title{
Alcohol and other substance use among medical and law students at a UK university: a cross-sectional questionnaire survey
}

\author{
Paul Bogowicz, ${ }^{1}$ Jennifer Ferguson, ${ }^{2}$ Eilish Gilvarry, ${ }^{1}$ Farhad Kamali, ${ }^{3}$ Eileen Kaner, ${ }^{1}$ \\ Dorothy Newbury-Birch ${ }^{2}$
}

- Additional material is published online only. To view please visit the journal online (http://dx.doi.org/10.1136/ postgradmedj-2017-135136).

${ }^{1}$ Institute of Health and Society, Newcastle University, Newcastle upon Tyne, UK

${ }^{2}$ School of Health \& Social Care, Teesside University, Middlesbrough, UK

${ }^{3}$ Institute of Cellular Medicine, Newcastle University, Newcastle upon Tyne, UK

Correspondence to Professor Dorothy NewburyBirch, School of Health \& Social Care, Teesside University,

Constantine Building, Middlesbrough, Tees Valley, TS1 3BA, UK;

d.newbury-birch@tees.ac.uk

Received 13 June 2017 Revised 4 October 2017 Accepted 21 October 2017

Published Online First

4 November 2017
Check for updates

To cite: Bogowicz $\mathrm{P}$, Ferguson J, Gilvarry E, et al. Postgrad Med J

2018;94:131-136.

\begin{abstract}
Purpose of the study To examine the use of alcohol and other substances among medical and law students at a UK university.
\end{abstract}

Study design Anonymous cross-sectional questionnaire survey of first, second and final year medical and law students at a single UK university.

Results 1242 of 1577 (78.8\%) eligible students completed the questionnaire. Over half of first and second year medical students (first year $53.1 \%$, second year $59.7 \%$, final year $35.9 \%$ ) had an Alcohol Use Disorders Identification Test (AUDIT) score suggestive of an alcohol use disorder (AUDIT $\geq 8$ ), compared with over two-thirds of first and second year law students (first year 67.2\%, second year 69.5\%, final year $47.3 \%$ ). Approximately one-quarter of medical students (first year $26.4 \%$, second year $28.4 \%$, final year $23.7 \%$ ) and over one-third of first and second year law students (first year $39.1 \%$, second year $42.4 \%$, final year $18.9 \%$ ) reported other substance use within the past year. Over one-third of medical students (first year $34.4 \%$, second year $35.6 \%$, final year $46.3 \%$ ) and approximately half or more of law students (first year $47.2 \%$, second year $52.7 \%$, final year $59.5 \%$ ) had a Hospital Anxiety and Depression Scale anxiety score suggestive of a possible anxiety disorder.

Conclusions Study participants had high levels of substance misuse and anxiety. Some students' fitness to practice may be impaired as a result of their substance misuse or symptoms of psychological distress. Further efforts are needed to reduce substance misuse and to improve the mental well-being of students.

\section{INTRODUCTION}

The misuse of alcohol and other substances has previously been shown to be common among university students in the UK. ${ }^{1-4}$ The consequences of alcohol misuse in particular include physical health problems and poor academic performance. ${ }^{56}$

There is comparatively little research looking at substance use among the distinct group of UK medical students. This is concerning, given that most medical students will go on to work as medical doctors. Doctors' own substance misuse may impair their fitness to practice and limit recognition of problem substance use in their own patients. ${ }^{7-10}$

There have not been any published reports looking at substance use among UK medical students since 2001; it is not known whether patterns of use have changed since then. Recent research from elsewhere in the world suggests that medical students' substance use is still an issue. ${ }^{11-15}$

Knowledge of current levels of substance use among UK medical students would inform preventive practice in this area. There is some evidence that hazardous drinking $(60 \mathrm{~g}$ of ethanol or more per drinking session at least 2-3 times per month) at medical school is predictive of later hazardous drinking, underscoring the importance of these efforts. $^{16}$

We carried out a prospective cross-sectional questionnaire survey in order to determine whether UK medical students' alcohol and other substance use has changed since 2001. We also aimed to determine how medical students' alcohol use relates to other substance use and mental health. We surveyed law students in order to compare patterns of use among medical students with those of students with similar professional and academic obligations.

\section{METHODS}

\section{Eligibility and recruitment}

The study took place at a single public university which has between 20000 and 30000 students. All first, second and final year medical and law students were eligible to participate. There were no exclusion criteria. Permission to survey the students was obtained from senior medical and law school officials.

Second and final year students were recruited in April 2014 and first year students in October 2014. These dates were chosen to match those of previous studies. ${ }^{17} 18 \mathrm{~A}$ member of the research team (JF) attended a compulsory lecture/seminar to explain the study and distribute the questionnaires. Students were given an anonymous paper questionnaire as well as a Change4Life (http://www.nhs. uk/change4life) leaflet and contact details for the university's student support service. Students were not permitted to take their questionnaire home or fill it in elsewhere. Students who were absent received an email with a link to an anonymous web version of the questionnaire, with three automatic reminder emails.

Participation in the study was voluntary; no financial incentive was given. Written consent was not obtained due to the anonymous nature of the study. Students were deemed to have given consent if they completed a paper or web questionnaire. 


\section{Questionnaire}

The questionnaire was based on one used by two of the study authors (DNB, FK) in previous studies. ${ }^{17} 18$ Participants were asked about their demographics, mental health, smoking and alcohol and other substance use. The questionnaire included: the 10-item Alcohol Use Disorders Identification Test (AUDIT), ${ }^{19}$ the 12-item General Health Questionnaire $(\mathrm{GHQ})^{20}$ and the Hospital Anxiety and Depression Scale (HADS). ${ }^{21}$

The AUDIT is considered to be the gold standard for alcohol screening in healthcare settings. ${ }^{22}$ The tool has previously been used to screen students. ${ }^{23}$ The AUDIT comprised of 10 questions and is scored on a scale of $0-40$. The questions can be grouped into three domains: recent alcohol use (1-3), dependence symptoms (4-6) and alcohol-related problems (7-10). ${ }^{24}$ A score of 8 or more is referred to as a positive screen and is suggestive of an underlying alcohol use disorder. A score of $8-15$ is suggestive of hazardous drinking, 16-19 harmful drinking and 20 or more dependent drinking. ${ }^{24}$ The AUDIT has a sensitivity and specificity of $92 \%$ and $94 \%$, respectively. ${ }^{19}$

The 12-item GHQ can be scored in a number of different ways. We used the GHQ scoring method (0-0-1-1), which is scored on a scale of $0-12$. A score of 2 or more is suggestive of an underlying psychiatric disorder. ${ }^{20}$

The HADS anxiety and depression components are scored separately on scales of $0-21$. A score of 8 or more for either component is suggestive of a possible anxiety or depressive disorder. ${ }^{21} 25$

The web version of the questionnaire was constructed using the Qualtrics platform (Qualtrics, Provo, Utah, USA). Both versions of the questionnaire were set out in the same manner.

\section{Measures}

The main outcome measures were AUDIT score and past year or lifetime use of other substances. Secondary outcome measures included smoking, GHQ score and HADS anxiety and depression scores.

\section{Statistical analysis}

Modifications to the raw data were limited to algebraic operations, continuous to categorical transformations and the combining of categories. Basic descriptive statistics were obtained to characterise demographics, mental health, smoking, alcohol use and other substance use.

Logistic regression analysis was used to examine factors associated with having a possible alcohol use disorder, as defined by an AUDIT score of 8 or more. We developed a model based on the results of two studies of medical students which found evidence of associations between smoking and cannabis use and alcohol misuse. ${ }^{1718}$ We included a term for smoking (never/ever) and a term for lifetime cannabis use (never/ever). We included terms for HADS anxiety and depression scores (0-7/8-21), as the impact of participants' mental health on their alcohol use was of interest to us. The model also included demographic variables-age (continuous), ethnicity (non-white/white) and gender (female/male) (categorical). We did not use stepwise variable addition or elimination. Separate models were obtained for each year group. Goodness of fit was assessed using the Hosmer-Lemeshow test. Collinearity was measured using the variance inflation factor. Second and final year law students were excluded from this part of the analysis because of their small group sample sizes.

$P$ values less than 0.05 were considered to be significant. Missing values were excluded from statistics and statistical tests.
All analyses were carried out using SPSS software V.23 and V.24 (IBM, Armonk, New York, USA).

\section{RESULTS}

\section{Study sample}

The questionnaire was completed by 1242 of 1577 (78.8\%) eligible medical and law students. The response rates for first, second and final year medical students were 100\% (313/313), $94.5 \%$ (311/329) and $74.0 \%$ (265/358), respectively. The response rates for first, second and final year law students were $85.9 \%(201 / 234), 54.5 \%(110 / 202)$ and $29.8 \%(42 / 141)$, respectively. We were unable to determine whether survey respondents differed from non-respondents due to the anonymous nature of the study.

\section{Demographics}

Demographic details are presented in table 1. We compared our sample to the corresponding Higher Education Statistics Agency demographic profiles for $2013 / 14 .{ }^{26}$ The percentages of female students in all medical student and the first and second year law student groups were similar to the UK averages of $56.2 \%$ for medical/dental students and $60.5 \%$ for law students, respectively. The percentage of female final year law students was higher in our sample. The percentages of ethnic minority background students were lower among final year medical and second year law students, compared with the UK averages of $32.5 \%$ for medical/dental students and $33.3 \%$ for law students.

\section{Mental health}

Participant GHQ and HADS scores are presented in table 1. Over half of first and final year medical students (first year $50.2 \%$, second year $45.3 \%$, final year 54.9\%) and all law student groups (first year 54.0\%, second year 56.8\%, final year 68.4\%) had a GHQ score suggestive of a psychiatric disorder. Over one-third of medical students (first year 34.4\%, second year 35.6\%, final year $46.3 \%$ ) and approximately half or more of law students (first year 47.2\%, second year 52.7\%, final year 59.5\%) had a HADS anxiety score suggestive of a possible anxiety disorder. Over one-tenth of final year medical (first year 7.3\%, second year $8.5 \%$, final year $13.0 \%$ ) and second and final year law students (first year 9.4\%, second year $13.5 \%$, final year $10.8 \%$ ) had a HADS depression score suggestive of significant depression.

More second and final year medical students (first year $2.4 \%$, second year $7.7 \%$, final year $8.8 \%$ ) were prescribed sedatives or antidepressants in the past year, compared with law students (first year $4.8 \%$, second year $5.4 \%$, final year $2.7 \%$ ).

\section{Smoking}

Figures for smoking are presented in table 2. The prevalence of current smoking was lower among medical students (first year $2.6 \%$, second year $4.8 \%$, final year $3.5 \%$ ), compared with law students (first year $10.6 \%$, second year $19.0 \%$, final year $12.5 \%$ ).

\section{Alcohol use}

Participant AUDIT scores are presented in table 2. Over half of first and second year medical students (first year 53.1\%, second year 59.6\%, final year 35.9\%) scored positive for an alcohol use disorder, compared with over two-thirds of first and second year law students (first year 67.2\%, second year 69.5\%, final year $47.4 \%$ ). More than one-tenth of first and second year law students had scores indicative of alcohol dependence. Median AUDIT scores were lower among medical students (first year 8, 
Table 1 Demographics and mental health, by group and year

\begin{tabular}{|c|c|c|c|c|c|c|c|}
\hline Variable & Values & $\begin{array}{l}\text { Medicine first year, } \\
\mathrm{n}(\%)\end{array}$ & $\begin{array}{l}\text { Medicine } \\
\text { second year, n (\%) }\end{array}$ & $\begin{array}{l}\text { Medicine final } \\
\text { year, } \mathrm{n}(\%)\end{array}$ & $\begin{array}{l}\text { Law first year, } \mathrm{n} \\
(\%)\end{array}$ & $\begin{array}{l}\text { Law second year } \mathbf{n} \\
(\%)\end{array}$ & $\begin{array}{l}\text { Law final year, } \\
\mathrm{n}(\%)\end{array}$ \\
\hline \multirow[t]{5}{*}{ Age } & $\leq 19$ & $251(85.7)$ & $71(24.8)$ & $0(0)$ & $155(83.3)$ & $28(30.4)$ & $1(2.7)$ \\
\hline & $20-24$ & $36(12.3)$ & $200(69.9)$ & $164(66.7)$ & $27(14.5)$ & $63(68.5)$ & $33(89.2)$ \\
\hline & $25-29$ & $5(1.7)$ & $11(3.8)$ & $72(29.3)$ & $4(2.2)$ & $0(0)$ & $3(8.1)$ \\
\hline & $30-34$ & $0(0)$ & $3(1.0)$ & $8(3.3)$ & $0(0)$ & $1(1.1)$ & $0(0)$ \\
\hline & $\geq 35$ & $1(0.3)$ & $1(0.3)$ & $2(0.8)$ & $0(0)$ & $0(0)$ & $0(0)$ \\
\hline \multirow[t]{2}{*}{ Gender } & Female & $149(50.9)$ & $149(52.1)$ & $141(56.9)$ & $115(61.8)$ & $57(62.0)$ & $30(78.9)$ \\
\hline & Male & $144(49.1)$ & $137(47.9)$ & $107(43.1)$ & 71 (38.2) & $35(38.0)$ & $8(21.1)$ \\
\hline \multirow[t]{7}{*}{ Ethnicity } & White & $209(71.3)$ & $216(75.8)$ & $199(80.2)$ & $140(75.7)$ & $82(89.1)$ & $29(78.4)$ \\
\hline & Black & $8(2.7)$ & $1(0.4)$ & $8(3.2)$ & 7 (3.8) & $1(1.1)$ & $1(2.7)$ \\
\hline & Asian & $48(16.4)$ & $35(12.3)$ & $19(7.7)$ & $16(8.6)$ & $1(1.1)$ & $3(8.1)$ \\
\hline & Chinese & $11(3.8)$ & $15(5.3)$ & $11(4.4)$ & $14(7.6)$ & $2(2.2)$ & $3(8.1)$ \\
\hline & Mixed & $14(4.8)$ & $15(5.3)$ & $10(4.0)$ & $5(2.7)$ & $4(4.3)$ & $1(2.7)$ \\
\hline & Other & $3(1.0)$ & $3(1.1)$ & $1(0.4)$ & $3(1.6)$ & $1(1.1)$ & $0(0)$ \\
\hline & Not known & $0(0)$ & $0(0)$ & $0(0)$ & $0(0)$ & $1(1.1)$ & $0(0)$ \\
\hline \multirow[t]{2}{*}{ GHQ } & $0-1$ & $145(49.8)$ & $156(54.7)$ & $111(45.1)$ & $86(46.0)$ & $38(43.2)$ & 12 (31.6) \\
\hline & $2-12$ & $146(50.2)$ & $129(45.3)$ & $135(54.9)$ & $101(54.0)$ & $50(56.8)$ & $26(68.4)$ \\
\hline \multirow[t]{3}{*}{ HADS-Anxiety } & $0-7$ & $189(65.6)$ & $181(64.4)$ & $132(53.7)$ & $95(52.8)$ & $43(47.3)$ & $15(40.5)$ \\
\hline & $8-10$ & $54(18.8)$ & 48 (17.1) & $56(22.8)$ & $46(25.6)$ & $23(25.3)$ & $10(27.0)$ \\
\hline & $11-21$ & $45(15.6)$ & $52(18.5)$ & $58(23.6)$ & $39(21.7)$ & $25(27.5)$ & 12 (32.4) \\
\hline \multirow[t]{3}{*}{ HADS-Depression } & $0-7$ & $267(92.7)$ & $259(91.5)$ & $214(87.0)$ & $163(90.6)$ & 77 (86.5) & $33(89.2)$ \\
\hline & $8-10$ & $12(4.2)$ & $15(5.3)$ & $17(6.9)$ & $12(6.7)$ & $8(9.0)$ & $2(5.4)$ \\
\hline & $11-21$ & $9(3.1)$ & $9(3.2)$ & $15(6.1)$ & $5(2.8)$ & $4(4.5)$ & $2(5.4)$ \\
\hline
\end{tabular}

GHQ, General Health Questionnaire; HADS, Hospital Anxiety and Depression Scale.

second year 9, final year 6) compared with law students (first year 11 , second year 10 , final year 7 ).

A breakdown of AUDIT scores is given in online supplementary table 1 . The higher scores among second year medical students appear to be driven by higher typical quantities, more frequent impaired control over drinking and increased salience of drinking and a greater burden of alcohol-related problems (apart from injuries). The higher scores among first year law students appear to be driven by greater proportions of these students reporting drinking four or more times a week, typically drinking seven or more drinks and weekly or daily/almost daily heavy drinking compared with medical students. Higher scores among second year law students appear to be driven by a wider range of reported behaviours. Greater proportions of law students in all three year groups reported recent alcohol-related injuries compared with medical students.

\section{Other substance use}

Approximately one-quarter of medical students (first year $26.4 \%$, second year $28.4 \%$, final year $23.7 \%$ ) and over one-third of first and second year law students (first year 39.1\%, second year $42.4 \%$, final year $18.9 \%$ ) reported other substance use within the past year (table 3). Cannabis was the most commonly used substance. The second and third most commonly used substances were cocaine, ecstasy and nitrous oxide. The prevalence of lifetime use of other substances was highest among final year medical (first year 35.1\%, second year 39.1\%, final year 57.0\%) and first and second year law students (first year $45.7 \%$, second year $52.7 \%$, final year $26.3 \%$ ). The three most commonly used substances were the same as for past year use.

\section{Regression analysis}

Among first year medical and first year law students, age, cannabis use, ethnicity and smoking were significantly associated with having a possible alcohol use disorder (AUDIT $\geq 8$ ) (table 4). Among second year medical students, cannabis use, ethnicity and smoking were significant. Among final year medical students, only cannabis use and HADS depression score were significant. All significant associations were positive apart from those for age and HADS depression score.

Table 2 Smoking and alcohol use, by group and year

\begin{tabular}{|c|c|c|c|c|c|c|c|}
\hline Variable & Values & $\begin{array}{l}\text { Medicine first } \\
\text { year, } \mathrm{n}(\%)\end{array}$ & $\begin{array}{l}\text { Medicine second year, } \\
\text { n (\%) }\end{array}$ & $\begin{array}{l}\text { Medicine final } \\
\text { year, } \mathrm{n}(\%)\end{array}$ & Law first year, $\mathrm{n}(\%)$ & $\begin{array}{l}\text { Law second } \\
\text { year, } \mathrm{n}(\%)\end{array}$ & $\begin{array}{l}\text { Law final year, } n \\
(\%)\end{array}$ \\
\hline \multirow[t]{4}{*}{ Smoking } & Never & $171(56.4)$ & $131(44.9)$ & $101(39.6)$ & $72(38.1)$ & $32(32.0)$ & $15(37.5)$ \\
\hline & Tried a few & $117(38.6)$ & $136(46.6)$ & $129(50.6)$ & $85(45.0)$ & $44(44.0)$ & $18(45.0)$ \\
\hline & Ex-regular & $7(2.3)$ & $11(3.8)$ & $16(6.3)$ & $12(6.3)$ & $5(5.0)$ & $2(5.0)$ \\
\hline & Current & $8(2.6)$ & $14(4.8)$ & $9(3.5)$ & $20(10.6)$ & $19(19.0)$ & $5(12.5)$ \\
\hline \multirow[t]{5}{*}{ AUDIT score } & Negative (0-7) & $137(46.9)$ & $113(40.4)$ & $159(64.1)$ & $60(32.8)$ & $29(30.5)$ & $20(52.6)$ \\
\hline & Hazardous (8-15) & $128(43.8)$ & $120(42.9)$ & $84(33.9)$ & $71(38.8)$ & $43(45.3)$ & $16(42.1)$ \\
\hline & Harmful (16-19) & $16(5.5)$ & $25(8.9)$ & $2(0.8)$ & $22(12.0)$ & $13(13.7)$ & $1(2.6)$ \\
\hline & Dependence (20-40) & $11(3.8)$ & $22(7.9)$ & $3(1.2)$ & $30(16.4)$ & $10(10.5)$ & $1(2.6)$ \\
\hline & Positive (8-40) & 155 (53.1) & 167 (59.6) & 89 (35.9) & $123(67.2)$ & 66 (69.5) & $18(47.4)$ \\
\hline
\end{tabular}

AUDIT, Alcohol Use Disorders Identification Test. 
Table 3 Other substance use, by group and year

\begin{tabular}{|c|c|c|c|c|c|c|c|}
\hline Variable & Values & $\begin{array}{l}\text { Medicine first } \\
\text { year, } \mathrm{n}(\%)\end{array}$ & $\begin{array}{l}\text { Medicine second } \\
\text { year, } \mathrm{n}(\%)\end{array}$ & $\begin{array}{l}\text { Medicine final } \\
\text { year, } n(\%)\end{array}$ & $\begin{array}{l}\text { Law first year, } \mathrm{n} \\
(\%)\end{array}$ & $\begin{array}{l}\text { Law second year, } n \\
(\%)\end{array}$ & $\begin{array}{l}\text { Law final year, } n \\
(\%)\end{array}$ \\
\hline \multirow[t]{2}{*}{ Any } & Past year & $78(26.4)$ & $81(28.4)$ & $59(23.7)$ & $72(39.1)$ & $39(42.4)$ & $7(18.9)$ \\
\hline & Lifetime & $104(35.1)$ & $110(39.1)$ & $142(57.0)$ & $84(45.7)$ & $49(52.7)$ & $10(26.3)$ \\
\hline \multirow[t]{2}{*}{ Amphetamines } & Past year & $5(1.7)$ & $2(0.7)$ & $7(2.8)$ & $9(4.9)$ & $8(8.8)$ & $1(2.7)$ \\
\hline & Lifetime & $7(2.4)$ & $8(2.9)$ & $17(6.9)$ & $7(3.8)$ & $8(8.7)$ & $2(5.3)$ \\
\hline \multirow[t]{2}{*}{ Anabolic steroids } & Past year & $1(0.3)$ & $0(0)$ & $0(0)$ & $0(0)$ & $0(0)$ & $0(0)$ \\
\hline & Lifetime & $1(0.3)$ & $0(0)$ & $1(0.4)$ & $2(1.1)$ & $0(0)$ & $0(0)$ \\
\hline \multirow{2}{*}{$\begin{array}{l}\text { Benzodiazepines or } \\
\text { Z-drugs }\end{array}$} & Past year & $5(1.7)$ & $4(1.4)$ & $6(2.4)$ & $3(1.6)$ & $3(3.3)$ & $1(2.7)$ \\
\hline & Lifetime & $6(2.0)$ & $4(1.4)$ & $13(5.3)$ & $3(1.7)$ & $3(3.3)$ & $0(0)$ \\
\hline \multirow[t]{2}{*}{ Cannabis } & Past year & $66(22.4)$ & 68 (23.9) & $46(18.5)$ & $56(30.4)$ & $34(37.4)$ & $6(16.2)$ \\
\hline & Lifetime & $89(30.3)$ & $99(35.2)$ & $132(53.0)$ & $74(40.4)$ & $47(50.5)$ & $10(26.3)$ \\
\hline \multirow[t]{2}{*}{ Cathinones } & Past year & $1(0.3)$ & $3(1.1)$ & $1(0.4)$ & $3(1.6)$ & $3(3.3)$ & $0(0)$ \\
\hline & Lifetime & $3(1.0)$ & $7(2.5)$ & $16(6.6)$ & $3(1.7)$ & $4(4.4)$ & $0(0)$ \\
\hline \multirow[t]{2}{*}{ Cocaine } & Past year & $12(4.1)$ & $11(3.9)$ & $13(5.3)$ & $14(7.7)$ & $13(14.3)$ & $3(8.1)$ \\
\hline & Lifetime & $12(4.1)$ & $12(4.3)$ & $37(15.1)$ & $17(9.3)$ & $12(13.0)$ & $3(7.9)$ \\
\hline \multirow[t]{2}{*}{ Ecstasy } & Past year & $18(6.1)$ & $27(9.5)$ & $11(4.4)$ & $20(10.9)$ & $18(20.0)$ & $4(10.8)$ \\
\hline & Lifetime & $23(7.9)$ & $32(11.4)$ & $34(13.8)$ & $24(13.2)$ & $24(25.8)$ & $6(15.8)$ \\
\hline \multirow[t]{2}{*}{$\mathrm{GBL}$ or $\mathrm{GHB}$} & Past year & $2(0.7)$ & $1(0.4)$ & $1(0.4)$ & $0(0)$ & $1(1.1)$ & $0(0)$ \\
\hline & Lifetime & $3(1.0)$ & $1(0.4)$ & $0(0)$ & $0(0)$ & $1(1.1)$ & $0(0)$ \\
\hline \multirow[t]{2}{*}{ Ketamine } & Past year & $6(2.0)$ & $6(2.1)$ & $4(1.6)$ & $7(3.8)$ & $9(10.0)$ & $1(2.7)$ \\
\hline & Lifetime & $6(2.1)$ & $9(3.2)$ & $19(7.8)$ & $8(4.4)$ & $10(10.9)$ & $2(5.3)$ \\
\hline \multirow[t]{2}{*}{ LSD } & Past year & $6(2.1)$ & $0(0)$ & $3(1.2)$ & $5(2.7)$ & $3(3.3)$ & $1(2.8)$ \\
\hline & Lifetime & $7(2.4)$ & $1(0.4)$ & $4(1.7)$ & $7(3.9)$ & $4(4.3)$ & $2(5.3)$ \\
\hline \multirow[t]{2}{*}{ Mushrooms } & Past year & $9(3.1)$ & $13(4.6)$ & $1(0.4)$ & $5(2.7)$ & $4(4.4)$ & $2(5.4)$ \\
\hline & Lifetime & $12(4.1)$ & $18(6.5)$ & $21(8.6)$ & $6(3.3)$ & $8(8.7)$ & $2(5.3)$ \\
\hline \multirow[t]{2}{*}{ Nitrous oxide } & Past year & $26(8.9)$ & $26(9.2)$ & $11(4.5)$ & $29(15.8)$ & $10(11.2)$ & $3(8.1)$ \\
\hline & Lifetime & $30(10.2)$ & 31 (11.1) & $22(9.1)$ & $29(15.9)$ & 10 (11.1) & $2(5.3)$ \\
\hline \multirow[t]{2}{*}{ Opioids } & Past year & $2(0.7)$ & $1(0.4)$ & $1(0.4)$ & $1(0.6)$ & $0(0)$ & $0(0)$ \\
\hline & Lifetime & $4(1.4)$ & $4(1.4)$ & $5(2.1)$ & $3(1.7)$ & $0(0)$ & $0(0)$ \\
\hline \multirow[t]{2}{*}{ Piperazines } & Past year & $2(0.7)$ & $0(0)$ & $0(0)$ & $0(0)$ & $2(2.2)$ & $0(0)$ \\
\hline & Lifetime & $2(0.7)$ & $0(0)$ & $0(0)$ & $0(0)$ & $2(2.2)$ & $0(0)$ \\
\hline \multirow{2}{*}{$\begin{array}{l}\text { Synthetic } \\
\text { cannabinoids }\end{array}$} & Past year & $1(0.3)$ & $1(0.4)$ & $0(0)$ & $4(2.2)$ & $2(2.2)$ & $0(0)$ \\
\hline & Lifetime & $1(0.3)$ & $2(0.7)$ & $1(0.4)$ & $1(0.6)$ & $4(4.4)$ & $0(0)$ \\
\hline
\end{tabular}

GBL, gamma butyrolactone; GHB, gamma hydroxybutyric acid; LSD, lysergic acid diethylamide.

\section{DISCUSSION}

We found that 53\%, 60\% and 36\% of first, second and final year medical students, respectively, scored positive for an alcohol use disorder. This compares to $57 \%$ and $47 \%$ for second and final year students, respectively, in a previous UK study. ${ }^{27}$ In contrast, one longitudinal UK study found that the prevalence of alcohol misuse increased over time. ${ }^{18}$ Our findings suggest that medical students are less likely to engage in drinking patterns suggestive of an alcohol use disorder, compared with law students. The results of our regression analyses suggest that a culture of drinking among university students may lead to more homogenised patterns of alcohol consumption among those with differing backgrounds. This is in keeping with previous research which suggests that some students come to university with pre-existing high levels of alcohol misuse. ${ }^{17}$

We found that $26 \%, 28 \%$ and $24 \%$ of first, second and final year medical students, respectively, reported using other substances within the past year. Cannabis was by far the most commonly used substance. These figures are similar to those found for cannabis use in two UK studies ${ }^{17}{ }^{18}$ but lower than the $33 \%$ reported for illicit substance use among the students in another UK study. ${ }^{28}$ Our findings suggest that the prevalence of other substance use among medical students is less than that of the law students at the same university. This suggests that perhaps medical students are more aware of the possible dangers of other substance use. Indeed, we found that the prevalence of novel psychoactive substance use, apart from nitrous oxide, was low.

The prevalence of a possible anxiety disorder was higher among the final year medical students in our study (46\%) compared with a previous UK study $(28 \%) .{ }^{18}$ The prevalence of a possible depressive disorder was also higher (13\% vs $5 \%) .^{18}$ Final year medical students with a HADS depression score suggestive of a possible depressive disorder were less likely to have a possible alcohol use disorder. This was not found in other UK studies. ${ }^{18} 28$ The medical profession is under much strain, and it could be that stress-related mood symptoms and excessive drinking are related to these work pressures. Indeed, burnout and stress have been shown to be related to excessive drinking among medical students elsewhere. ${ }^{29}$

Study strengths include the anonymous nature of data collection and the good response rates among medical and first year law students. Study findings are comparable to previous UK studies. ${ }^{1718}$ Our study has limitations. The response rate for final year medical students was relatively low. Time pressure may have been a factor as students were surveyed the month 
Table 4 Logistic regression analysis for having a possible alcohol use disorder (AUDIT $\geq 8$ ), by group and year

\begin{tabular}{|c|c|c|c|c|c|c|c|c|}
\hline \multirow[t]{2}{*}{ Variable } & \multicolumn{2}{|l|}{ Medicine first year } & \multicolumn{2}{|c|}{ Medicine second year } & \multicolumn{2}{|l|}{ Medicine final year } & \multicolumn{2}{|l|}{ Law first year } \\
\hline & OR $(95 \% \mathrm{Cl})$ & $P$ value & OR $(95 \% \mathrm{Cl})$ & $P$ value & OR $(95 \% \mathrm{Cl})$ & $P$ value & OR $(95 \% \mathrm{Cl})$ & $P$ value \\
\hline \multicolumn{9}{|l|}{ Age } \\
\hline Continuous & 0.72 (0.58 to 0.89 ) & 0.002 & 0.92 (0.82 to 1.03 ) & 0.161 & 1.02 (0.92 to 1.14$)$ & 0.724 & 0.71 (0.54 to 0.93 ) & 0.013 \\
\hline \multicolumn{9}{|l|}{ Cannabis use } \\
\hline Never & 1 (reference) & 0.035 & 1 (reference) & 0.032 & 1 (reference) & 0.001 & 1 (reference) & 0.032 \\
\hline Ever & 2.17 (1.06 to 4.48$)$ & & 2.15 (1.07 to 4.34 ) & & 3.19 (1.61 to 6.33$)$ & & 2.99 (1.10 to 8.14$)$ & \\
\hline \multicolumn{9}{|l|}{ Ethnicity } \\
\hline Non-white & 1 (reference) & $<0.001$ & 1 (reference) & 0.003 & 1 (reference) & 0.118 & 1 (reference) & $<0.001$ \\
\hline White & 3.58 (1.84 to 6.98$)$ & & 2.70 (1.41 to 5.15$)$ & & 1.96 (0.84 to 4.55$)$ & & 6.60 (2.56 to 16.99$)$ & \\
\hline \multicolumn{9}{|l|}{ Gender } \\
\hline Female & 1 (reference) & 0.613 & 1 (reference) & 0.510 & 1 (reference) & 0.089 & 1 (reference) & 0.716 \\
\hline Male & 1.16 (0.65 to 2.08$)$ & & 1.21 (0.69 to 2.13 ) & & 1.68 (0.92 to 3.07$)$ & & 1.17 (0.50 to 2.77$)$ & \\
\hline \multicolumn{9}{|l|}{ HADS-Anxiety } \\
\hline $0-7$ & 1 (reference) & 0.064 & 1 (reference) & 0.840 & 1 (reference) & 0.101 & 1 (reference) & 0.799 \\
\hline 8-21 & 0.54 (0.28 to 1.04$)$ & & 0.94 (0.50 to 1.75 ) & & 1.69 (0.90 to 3.17 ) & & 1.12 (0.48 to 2.60$)$ & \\
\hline \multicolumn{9}{|c|}{ HADS-Depression } \\
\hline $0-7$ & 1 (reference) & 0.575 & 1 (reference) & 0.968 & 1 (reference) & 0.017 & 1 (reference) & 0.966 \\
\hline $8-21$ & 1.46 (0.39 to 5.50$)$ & & 1.02 (0.35 to 2.96$)$ & & $0.28(0.10$ to 0.80$)$ & & 1.03 (0.24 to 4.39$)$ & \\
\hline \multicolumn{9}{|l|}{ Smoking } \\
\hline Never & 1 (reference) & $<0.001$ & 1 (reference) & $<0.001$ & 1 (reference) & 0.130 & 1 (reference) & 0.031 \\
\hline Ever & 5.80 (2.92 to 11.52$)$ & & 4.10 (2.21 to 7.63$)$ & & 1.77 (0.85 to 3.70$)$ & & 2.66 (1.09 to 6.49$)$ & \\
\hline
\end{tabular}

AUDIT, Alcohol Use Disorders Identification Test; HADS, Hospital Anxiety and Depression Scale.

before their final examinations. Also, there were no compulsory lectures during the survey period. The response rates for second and final year law students were very low. We were unable to determine whether survey non-responders differed from responders. We note that there is also the potential for recall and social desirability biases. Our figures are likely to underestimate the true prevalence of substance misuse in the context of significant social desirability bias. There may be differences between the students in our study and those from other universities, and this may limit generalisability.

The medical and law students in our sample had high levels of alcohol and other substance misuse. These students are at

\section{Main messages}

- The prevalence of alcohol and other substance misuse is high among medical and law students at a single UK university.

- First and second year medical students appear to be less likely to misuse substances, compared with law students at the same university.

- Further efforts are needed to reduce substance misuse and to improve the mental well-being of students.

\section{Current research questions}

- What is the trajectory of alcohol use among those transitioning from UK medical schools to professional practice?

- How do UK medical students' attitudes toward alcohol and other substance use relate to their patterns of use over time?

- What interventions are most effective in reducing substance misuse and promoting mental well-being among medical students? risk of substance-related harm. Many students also reported anxiety symptoms. Some students' fitness to practice may be impaired as a result of their substance misuse or symptoms of psychological distress, and this may jeopardise their career progression. It is important that medical and law students with substance use or mental health problems are given the support and treatment that they need. Randomised trials are needed to determine which interventions are effective in these groups. We note that the host university has developed a cross-university multidisciplinary alcohol working group in order to drive preventive work around alcohol consumption among students and staff. This group is seen as an example of good practice in the region.

Acknowledgements We would like to thank the students who participated in this research and the host university for kindly allowing us to survey their students

Contributors DN-B was the chief investigator, project manager and study guarantor. All members of the team helped to design the study, which was based on previous work carried out by DN-B and FK. JF collected and entered the data. PB analysed the data. All authors had access to the data. All authors contributed to the writing of the paper and approved the final manuscript.

Funding This study was funded by the host university. The funder had no role in the design of the study, collection of data, analysis of data, interpretation of data, writing of the paper and the decision to submit the paper for publication.

Disclaimer DN-B affirms that the manuscript is an honest, accurate and transparent account of the study being reported; that no important aspects of the study have been omitted and that any discrepancies from the study as planned have been explained.

Competing interests All authors have completed the ICMJE uniform disclosure form. EK has disclosed that she is employed by the host university. All other authors declare no support from any organization for the submitted work, no financial relationships with any organizations that might have an interest in the submitted work in the previous three years, no relationships or activities that could appear to have influenced the submitted work.

Ethics approval This study obtained ethical approval from the host university (reference number 00730/2014).

Provenance and peer review Not commissioned; externally peer reviewed. 
(C) Article author(s) (or their employer(s) unless otherwise stated in the text of the article) 2018. All rights reserved. No commercial use is permitted unless otherwise expressly granted.

\section{REFERENCES}

1 Webb E, Ashton CH, Kelly P, et al. Alcohol and drug use in UK university students. Lancet 1996:348:922-5.

2 Gill JS. Reported levels of alcohol consumption and binge drinking within the UK undergraduate student population over the last 25 years. Alcohol Alcohol 2002;37:109-20.

3 Heather N, Partington S, Partington E, et al. Alcohol use disorders and hazardous drinking among undergraduates at English universities. Alcohol Alcohol 2011;46:270-7.

4 Bennett TH, Holloway KR. Drug misuse among university students in the UK: implications for prevention. Subst Use Misuse 2014;49:448-55.

5 Mcgee R, Kypri K. Alcohol-related problems experienced by university students in New Zealand. Aust N Z J Public Health 2004;28:321-3.

6 Bewick BM, Mulhern B, Barkham M, et al. Changes in undergraduate student alcohol consumption as they progress through university. BMC Public Health 2008:8:163.

7 Weir E. Substance abuse among physicians. CMAJ 2000;162:1730.

8 Good doctors, safer patients: proposals to strengthen the system to assureand improve the performance of doctors and to protect the safety ofpatients. London: Department of Health, 2006. http://webarchive.nationalarchives.gov. uk/20130107105354/http://www.dh.gov.uk/prod_consum_dh/groups/dh_ digitalassets/@dh/@en/documents/digitalasset/dh_4137276.pdf (accessed 14 Mar 2016).

9 Kaner E, Rapley T, May C. Seeing through the glass darkly? A qualitative exploration of GPs' drinking and their alcohol intervention practices. Fam Pract 2006;23:481-7.

10 Harvey SB, Laird B, Henderson M, et al. The mental health of health care professionals: a review for the Department of Health. London: King's College London, 2009. http:// www.champspublichealth.com/writedir/8265The $\% 20$ Mental\%20Health\%20of\% 20 Health $\% 20$ Care $\% 20$ Professionals $\% 20-\% 20$ A $\% 20$ Review $\% 20$ by $\% 20$ the $\%$ 20DH\%20(June\%202009).pdf (accessed 14 Mar 2016).

11 Pham DB, Clough AR, Nguyen HV, et al. Alcohol consumption and alcohol-related problems among Vietnamese medical students. Drug Alcohol Rev 2010;29:219-26.

12 Ketoja J, Svidkovski AS, Heinälä P, et al. Risky drinking and its detection among medical students. Addict Behav 2013:38:2115-8.
13 Kudlow PA, Naylor KT, Xie B, et al. Cognitive enhancement in Canadian medical students. J Psychoactive Drugs 2013;45:360-5.

14 Trostler M, Li Y, Plankey MW. Prevalence of binge drinking and associated co-factors among medical students in a U.S. Jesuit University. Am J Drug Alcohol Abuse 2014;40:336-41.

15 Deressa W, Azazh A. Substance use and its predictors among undergraduate medical students of Addis Ababa University in Ethiopia. BMC Public Health 2011;11:660.

16 Mahmood JI, Grotmol KS, Tesli M, et al. Risk factors measured during medical school for later hazardous drinking: a 10-year, longitudinal, nationwide study (NORDOC). Alcohol Alcohol 2016;51:71-6.

17 Newbury-Birch D, White M, Kamali F. Factors influencing alcohol and illicit drug use amongst medical students. Drug Alcohol Depend 2000;59:125-30.

18 Newbury-Birch D, Walshaw D, Kamali F. Drink and drugs: from medical students to doctors. Drug Alcohol Depend 2001;64:265-70.

19 Saunders JB, Aasland OG, Babor TF, et al. Development of the alcohol use disorders identification test (AUDIT): WHO collaborative project on early detection of persons with harmful alcohol consumption-II. Addiction 1993:88:791-804.

20 Goldberg DP, Gater R, Sartorius N, et al. The validity of two versions of the GHQ in the WHO study of mental illness in general health care. Psychol Med 1997;27:191-7.

21 Zigmond AS, Snaith RP. The hospital anxiety and depression scale. Acta Psychiatr Scand 1983;67:361-70.

22 Hodgson R, Alwyn T, John B, et al. The fast alcohol screening test. Alcohol Alcohol 2002;37:61-6

23 Reinert DF, Allen JP. The alcohol use disorders identification test: an update of research findings. Alcohol Clin Exp Res 2007;31:185-99.

24 Babor TF, Higgins-Biddle JC, Saunders JB, et al. The alcohol use disorders identification test: guidelines for use in primary care. Geneva: World Health Organization, 2001. http://www.who.int/substance abuse/publications/audit/en/ (accessed 3 Oct 2017).

25 Bjelland I, Dahl AA, Haug TT, et al. The validity of the hospital anxiety and depression scale. An updated literature review. J Psychosom Res 2002;52:69-77.

26 Introduction - students 2013/14. Cheltenham: Higher Education Statistics Agency, 2015. https://www.hesa.ac.uk/data-and-analysis/publications/students-2013-14/ introduction (accessed 25 Oct 2016).

27 Granville-Chapman JE, Yu K, White PD. A follow-up survey of alcohol consumption and knowledge in medical students. Alcohol Alcohol 2001;36:540-3.

28 Pickard M, Bates L, Dorian M, et al. Alcohol and drug use in second-year medical students at the University of Leeds. Med Educ 2000;34:148-50.

29 Jackson ER, Shanafelt TD, Hasan 0, et al. Burnout and alcohol abuse/dependence among U.S. medical students. Acad Med 2016:91:1251-6.

9th-10th July 2018: University of Warwick Short Course "An Introduction to Immunology". A two day course for those seeking a grounding in immunology. The course will be informal but intensive with limited numbers to encourage interaction, questions and discussion. Suitable for personnel from the pharmaceutical industry, the medical community and academic scientists, although it would be appropriate for anyone seeking a grounding in immunology.

Details: Khyati Morjaria, School of Life Sciences, University of Warwick, Coventry, CV4 7AL, UK (Tel: 024765 75267; email: K.Morjaria@warwick.ac.uk; website: https://warwick.ac.uk/fac/sci/lifesci/study/ shortcourses/immunology). 